\title{
Effect of Fungi Isolated from Different Plastic Polluted Sites on Low Density Polyethylene Material Degradation with Reference to SEM Analysis
}

\author{
Jaya Philip ${ }^{1 *}$, Tanuja ${ }^{2}$, Harshita Michael ${ }^{1}$, Vanshika Verma ${ }^{1}$ and Anam Rahman ${ }^{1}$ \\ ${ }^{1}$ Department of Microbiology, Patna Women's College, Patna University, Patna, Bihar, India \\ ${ }^{2}$ Department of Botany, T. P. S. College, Patliputra University, Patna, Bihar, India
}

*Corresponding author

\begin{abstract}
A B S T R A C T
The use of plastics and their products have completely changed the human society. They are enormously used in medicines, food, cosmetics, transportation, etc. Plastics are complex polymers which take hundreds and thousands of years to degrade remaining in the environment and disturbing the ecosystem which are a part of it. LDPE is one of the thermoplastic polymers abundantly used for commercial purposes accounting for about $60 \%$ of the total plastic production. Under normal environmental conditions, such polymers might take millions of years to degrade completely. But with the use of effective microorganisms, the potential degradation of the polymer such as LDPE can be done efficiently under optimum lab conditions. The aim of this study was to isolate fungi from plastic polluted sites of Patna and to study their ability to degrade LDPE with reference to SEM analysis. The fungi were identified by studying their macroscopic and microscopic characteristics. Penicillium $s p$. was selected on the basis of the positive screening and was further used to study the degradation of LDPE sheets during a course of 15 and 30 days separately. Finally, after the end of the incubation period the percentage weight reduction of the LDPE sheets were calculated and weight reduction up to $20 \%$ and $50 \%$ after 15 and 30 days of incubation respectively was observed. Also, the shift in the $\mathrm{pH}$ of the MSM broth from neutral to acidic was seen. Finally, the degradation of LDPE sheets was confirmed by performing the SEM analysis which showed porosity and fragility on the surface of the sheets.
\end{abstract}

\section{Introduction}

The invention of plastics in the 19th century (Michel et al., 2012) and the wide range of plastic based products have revolutionized the human society. Almost every domain of our life involves their applications like transportation, production of food, medicine etc. as they are inexpensive and highly durable (Andrady and Neal, 2009). The word plastic originated from the Greek word "plastiko" meaning "Able to demold into various shapes" (Joel, 1995). Plastic constitute of carbon, hydrogen, silicon, oxygen, chlorine and nitrogen and is composed of the monomers linked together by chemical bond.

From the last three decades, the reckless and continuous usage of plastic product for packaging, industry, transportation, etc., in the urban and rural areas have raised serious 
problems of waste disposal of plastic and pollution caused by its use. The use of plastic has globally increased due to its durability, strength, inertness and low cost. But, the disadvantage of plastic is that it is difficult to be degraded completely through natural processes and persist in the environment for millions of years.

Plastic has toxic pollutants that damage the environment and cause land, water, and air pollution has direct and deadly effects on wildlife particularly the marine animals. According to a report published in 2019, plastic contribution to greenhouse gases is equivalent to 850 million tons of carbon dioxide $\left(\mathrm{CO}_{2}\right)$ to the atmosphere which are expected to increase to 1.34 billion tons by 2030 (Kiehl et al., 1997). The burning of plastic produces toxic gases like $\mathrm{CO}_{2}$ and Dioxins (Ali et al., 2009) and health hazards causing cancer and lung diseases (Pramila and Vijay, 2011).

The chemicals used in the manufacture of plastics are known to be toxic and can enter the food chain creating potential health risks (Talsness et al., 2009). In the year 1999-2000, as reported by Tiwari et al., (2000) that India has imported more than 12000 tons of plastics.

Depending on their chemical composition and varying properties related to absorption and adsorption, these factors contribute to the persistence of plastics (Barnes et al., 2009). Each polymer chain of plastic has several two thousand repeating units of these monomers, this complex nature of the polymers makes them highly stable and difficult to degrade (Jensen and William, 2008). The biodegradation of polythene is a slow process, microorganisms such as bacteria, fungi and actinomycetes are involved in the degradation of natural and synthetic plastic. Some of the crucial characteristics responsible for plastics resistance to biodegradation include their long chain polymer structure and high molecular weight along with hydrophobicity (Wilkes and Aristilde, 2017). Thus, the long chain polymers have to be first depolymerized or broken down into smaller monomers (Shah et al., 2008). The efficiency of biodegradation by microorganisms depended on a number of factors such as physical, chemical and biological agents of treatment, along with particular enzymes involved in the degradation of the polymer, the metabolic pathways responsible for the up taking the plastic fragments (Wilkes and Aristilde, 2017).

It was reported by Fourst et al., 1997 that common fungi participate in the biodegradation of plastics and similar results were obtained by El Shafei et al., (1998). In the recent year's microorganisms have been studied for their contribution in the degradation of plastics due to their ability to survive under various conditions and their abundance in different habitats where they are able to form stable consortia, exchange genetic material, mutate, accumulate of nutrients and protect against toxic substances (Rummel et al., 2017), these properties can be exploited in the degradation of plastic. Filamentous fungi have been reported to degrade polymers into simple compounds by using them as a carbon source (Kyaw et al., 2012).

Thermoplastic such as Low-Density Polyethylene (LDPE) are low density plastics that ranges from $0.910-0.940 \mathrm{gm} / \mathrm{cm}^{3}$, nonreactive at room temperature and can withstand $80^{\circ} \mathrm{C}$ continuously and $95^{\circ} \mathrm{C}$ for a short period of time (Pramila et al., 2011). LDPE is the one of the most abundant commercially produced polymers that accounts for about $60 \%$ of the total plastic production. 
They are resistant to biodegradation due to its long carbon chains (Contat-Rodrigo and Ribes Greus, 2002). Under normal environmental conditions it takes almost 10decades to mineralize the polymers (Otake et al., 1998). The use of polythene has increased over the years and its degradation is becoming a great challenge. Only a fraction of this polythene waste is recycled, and the others take hundreds of years to degraded (Barnes et al., 2009).

Biodegradation by utilizing effective microorganism is an attractive alternative for waste disposal and potentially much more efficient and does not produce secondary pollutants. In certain situations, it may even be possible to obtain useful end products with economic benefit from microbial metabolism of pollutants such as ethanol for use in biofuels (Iranzo, et al., 2001).

There has not been any convention methods developed for biodegradation on a commercial scale. However, research is still being conducted on the effectiveness in the biodegradation of polymers, using the metabolic potential of microorganisms, it is expected that it is not long before feasible biodegradation processes are developed. Microorganisms are capable of degrading the organic and inorganic materials and hence there is a lot interest in the microbial degradation of plastics and wastes (Raaman et al., 2012).

\section{Materials and Methods}

\section{Collection of soil sample from plastic dumping sites}

For collection of soil samples, the glass vials were sealed with aluminum foil and autoclaved at $121^{\circ} \mathrm{C}, 15 \mathrm{psi}$ for 30 minutes. The soil samples were collected $10 \mathrm{~cm}$ deep from the ground (Raaman et al., 2012) in the sterilized vials mainly from three different sites of Patna. The samples were brought to the laboratory safely.

\section{Isolation of fungi from collected soil sample and their identification}

The dilution of each soil sample was prepared and was inoculated by spread plate method on the PDA media. The plates were kept at $26^{\circ} \mathrm{C} \pm 0.2$ for $24-48$ hours in the incubator. The colonies were observed and counted. The fungal colonies were identified by studying their colony characteristics as well as microscopic characteristics by performing the Lacto phenol cotton blue staining. The macroscopic characteristics were studied by observing the colony characteristics like, colony shape, colony margin, colony color etc. The fungal colonies were picked up by the help of sterilized inoculating needle and placed on the slide, one drop of LPCB stain was added on the slide and the teasing of the fungal culture was done gently and cover slip was placed on the slide carefully allowing no air bubble to form under the cover slip. The slides were observed under the microscope at 10x and 40x magnifications.

\section{Screening of the polythene degrading fungi and the maintenance of pure culture}

The screening of LDPE degrading fungi was done by performing the clear zone formation test. Clear zone formation test is a semi quantitative approach to screen microorganisms able to depolymerize the polymers (Nishida and Tokiwa, 1993). For this MSM agar with $2 \mathrm{~g}$ of PEG powder added to it was prepared. The fungal cultures were streaked on the MSM agar and incubated at $26^{\circ} \mathrm{C} \pm 0.2$ for $24-36$ hours in duplicates. The fungal cultures able to form the clear zone around their colonies were selected as potential isolates and these cultures were maintained both on PDA and SDA media. 
Clear zone formation test is a semi quantitative approach to screen microorganisms able to depolymerize the polymers (Nishida and Tokiwa, 1993).

\section{Biodegradation of LDPE by selected isolates}

For biodegradation of LDPE, MSMB was prepared in the Erlenmeyer flasks and all the flasks containing the MSMB were inoculated with pre weighed LDPE sheets cut in the dimensions $1.5 \mathrm{~cm} \times 1.5 \mathrm{~cm}$ and sterilized with $70 \%$ ethanol for 5 minutes (Mukred et al., 2008) and then thoroughly rinsed with distilled water and two loops full of fungal cultures separately.

A control flask was also maintained with only LDPE sheet inoculated in the MSMB. All the flasks were incubated in the shaker incubator at $30^{\circ} \mathrm{C}$ and $120 \mathrm{rpm}$ for one month.

\section{Weight reduction analysis of LDPE degraded by fungal isolate}

After the end of the incubation period the flask were removed from the shaker incubator and the LDPE sheet was filtered out of the media, was washed with $70 \%$ ethanol for 5 minutes and then with distil water and dried in air. The final weight of the LDPE sheets was taken and the weight reduction percentage (refer to Table 3) was calculated by the formula,

Weight reduction $(\%)=($ Initial weight - Final weight) $\times 100 /$ Initial weight (Munir et al., 2018)

\section{Measure of change in the $\mathrm{pH}$ before and after the incubation}

The change in the $\mathrm{pH}$ of the media was measured before and after the incubation of the media inoculated with the fungal isolate containing the LDPE sheets incubated in the shaker incubator at $30^{\circ} \mathrm{C}$ and $120 \mathrm{rpm}$ for 15 days and 30 days respectively.

SEM analysis of the fungal degraded LDPE sheet

The SEM (Raaman et al., 2012)for the degraded LDPE sheet was performed at IIT Patna, Bihta. The samples were carried in to the SEM lab in the insulated bags, then the samples were taken out by the help of an aseptic forceps and were placed in the coating machine and finally the gold plating of the sample was done after which the specimen was placed on the stage of the scanning electron microscopy and was fixed properly and was connected to the computer system, after which the magnification, focus, fine resolution and the working voltage was set up with the help of the stage controller and finally the images were scanned.

\section{Results and Discussion}

Isolation of fungi from soil samples collected from plastic polluted sites in Patna

The fungal isolates were obtained from the soil samples collected aseptically from plastic polluted sites of Patna mainly from the industrial area of Patliputra, stadium area of Rajendranagar and plastic dumping sites near $\mathrm{PMCH}$.

The samples were brought to the laboratory under sterilized condition and after plating and incubation following observation was made. After studying the macroscopic characteristic (Table 1) and microscopic characteristics of the fungal colonies the isolates may be identified as Aspergillus sp, Rhizopus sp., Penicillium sp (Fig. 1 and 2) and Mucor sp. (Aneja, 2003), (Vaughan Gwynne H.C.I \&Barnes, 2004). 
Screening of polythene degrading fungi from the isolates obtained

The fungal colonies isolated and identified were streaked on MSM agar media supplemented with PEG powder and incubated at $26^{\circ} \mathrm{C}$ for 7 days in the incubator. Clear zone formation was seen in Aspergillus, Rhizopus and Pencillium. No zone was observed in case of Mucor sp (Table 2). Further, based on the results obtained the screening of the fungal isolates was done. Penicillium $s p$. Which showed maximum clear zone formation (Figure 3) was selected to study the ability to degrade LDPE sheets

\section{Weight reduction analysis of LDPE degraded by fungal isolate}

The final dry weight of the LDPE sheets placed into the MSM broth inoculated with the fungal culture was taken after incubation and the percentage weight reduction was calculated. As compared to the control the LDPE sheets showed a significant reduction of $20 \%$ after 15 days of incubation and $50 \%$ weight reduction after 30 days of incubation with Penicillium species (Table 3).

\section{Measure of change in the $\mathrm{pH}$}

The change in the $\mathrm{pH}$ of the media was measured before and after the incubation of the media inoculated with the fungal isolate and containing the LDPE. As compared to the control it was observed that there was a reduction in $\mathrm{pH}$ of the media after incubation of 15 days from neutral to 6.8. However, no further reduction was observed from 15 to 30 days (Table 4).

From the data provided it can be inferred that there was a drop in the value of $\mathrm{pH}$ after the incubation of the media with the fungal cultures. Similar results were obtained by Das. M.P et al., who studied the degradation of LDPE by Aspergillus sp. and Fusarium sp. and observed a shift of the $\mathrm{pH}$ from neutral to acidic after incubation of the MSM broth with fungal cultures.

Table.1 Characteristics of fungal colonies isolated and identified on PDA media

\begin{tabular}{|c|c|c|c|c|c|c|}
\hline \multirow{3}{*}{ Isolate } & \multicolumn{6}{|c|}{ Colony Morphology } \\
\hline & \multirow[t]{2}{*}{ Texture } & \multirow[t]{2}{*}{ Margin } & \multicolumn{2}{|c|}{ Colour } & \multirow[t]{2}{*}{ Elevation } & \multirow{2}{*}{$\begin{array}{c}\text { Microscopic } \\
\text { Characteristics }\end{array}$} \\
\hline & & & Front & Back & & \\
\hline Aspergillus sp. & Cottony & Irregular & Black & Off White & Raised & $\begin{array}{l}\text { Presence of Vesicles, } \\
\text { Conidiophores, Conidia } \\
\text { present in chains. }\end{array}$ \\
\hline Rhizopus sp. & Cottony & Regular & White & Off White & Raised & $\begin{array}{l}\text { Rhizoids, sporangiosphore, } \\
\text { Sporangia and spores } \\
\text { present. }\end{array}$ \\
\hline Penicillium sp & Cottony & Regular & Green & Creamy & Raised & $\begin{array}{l}\text { Presence of chain of conidia } \\
\text { bearing conidiophores, } \\
\text { branched, brush like } \\
\text { appearance }\end{array}$ \\
\hline Mucor sp & Cottony & Irregular & White & Off White & Raised & $\begin{array}{l}\text { Sporangium and } \\
\text { sporangiosphore present, no } \\
\text { rhizoids seen }\end{array}$ \\
\hline
\end{tabular}


Table.2 Diameter of clear zone formation by the fungal isolates on MSM agar supplemented with PEG

\begin{tabular}{|c|c|c|}
\hline Isolates & Clear zone formation & Diameter $(\mathbf{c m})$ \\
\hline Aspergillus $\boldsymbol{s p}$. & + & 1.1 \\
\hline Rhizopus $\boldsymbol{s p}$. & + & 1.1 \\
\hline Penicillium $\boldsymbol{s p}$. & + & 1.4 \\
\hline Mucor $\boldsymbol{s p}$. & - & 0.0 \\
\hline
\end{tabular}

Table.3 Percentage weight reduction of LDPE sheets placed in MSM broth inoculated with Penicillium

\begin{tabular}{|c|c|c|c|c|c|c|}
\hline Sample Polymer used & Isolate & Initial Weight & \multicolumn{2}{|c|}{ Final Weight } & \multicolumn{2}{|c|}{$\begin{array}{c}\text { Percent weight } \\
\text { reduction }\end{array}$} \\
\cline { 4 - 6 } & & & 15 days & $\mathbf{3 0}$ days & $\mathbf{1 5}$ days & $\mathbf{3 0}$ days \\
\hline LDPE Sheets & Penicillium $s p$. & $30 \mathrm{mg}$ & $24 \mathrm{mg}$ & $15 \mathrm{mg}$ & $20.0 \%$ & $50.0 \%$ \\
\hline LDPE Sheets & Control & $30 \mathrm{mg}$ & $30 \mathrm{mg}$ & $30 \mathrm{mg}$ & 0 & 0 \\
\hline
\end{tabular}

Table.4 Change in the $\mathrm{pH}$ of the media after incubation of the media inoculated with the fungal isolate and containing the LDPE

\begin{tabular}{|c|c|c|c|}
\hline Isolate inoculated in the media & pH before inoculation & \multicolumn{2}{|c|}{$\mathbf{p H}$ after inoculation } \\
\cline { 3 - 4 } & & $\mathbf{1 5 d a y s}$ & 30days \\
\hline Penicillium $\boldsymbol{s p}$. & 7.0 & 6.8 & 6.8 \\
\hline Control & 7.0 & 7.0 & 7.0 \\
\hline
\end{tabular}

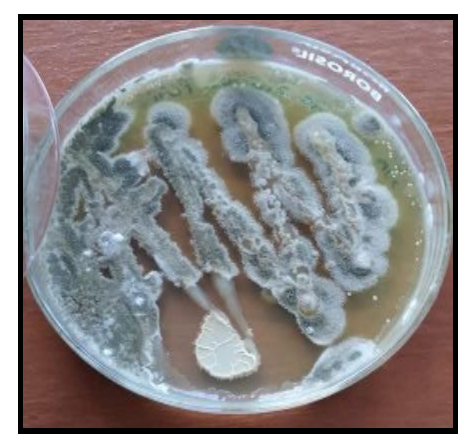

Figure.1 Cultural characteristics of Penicillium sp. on PDA media

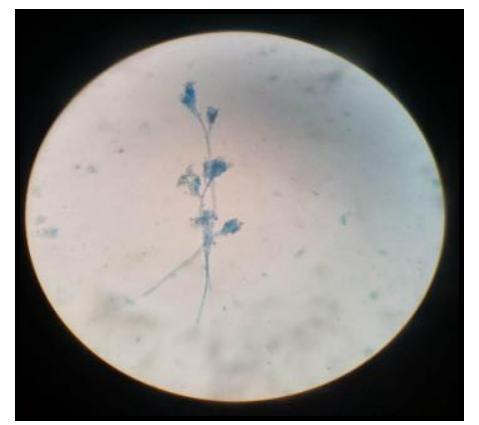

Figure.2 Microscopic view of Penicillium sp. under 40x magnification 


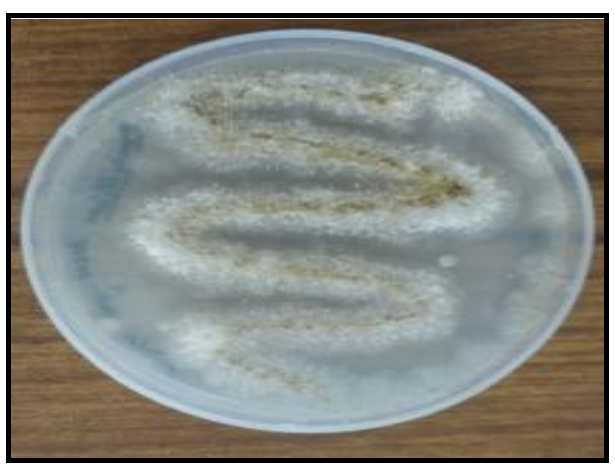

Figure.3 Penicillium sp. showing maximum clear zone around colony growth

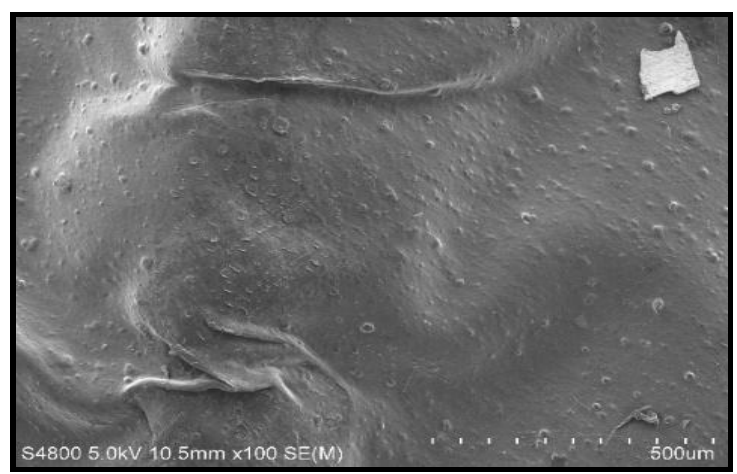

Figure.4 SEM image for control LDPE sheet showing no degradation

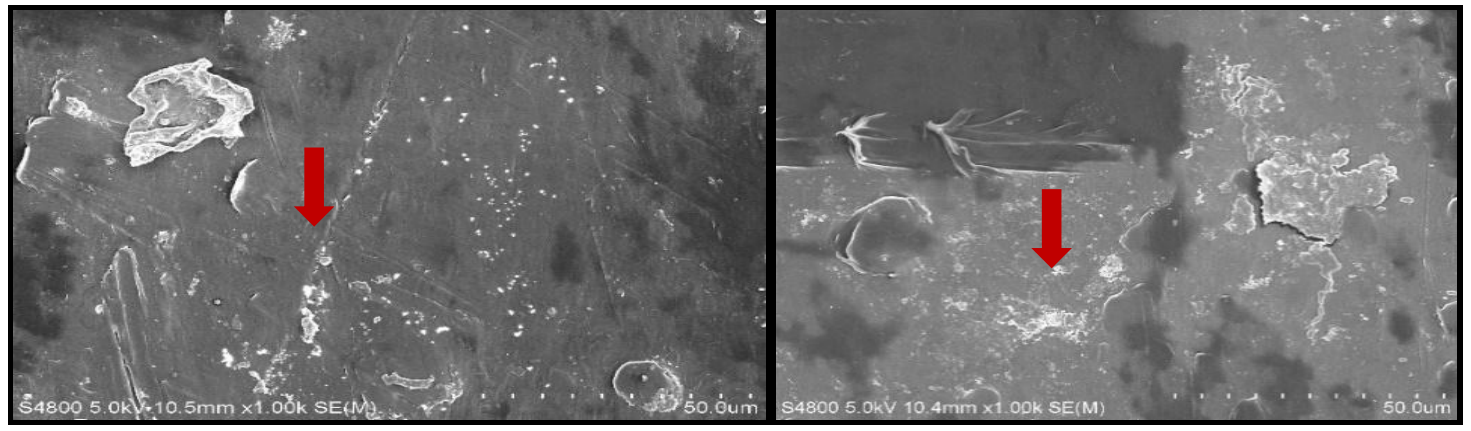

Figure.5 (a) SEM images showing degradation of LDPE sheet on two different sites by Penicillium sp. after 15 days

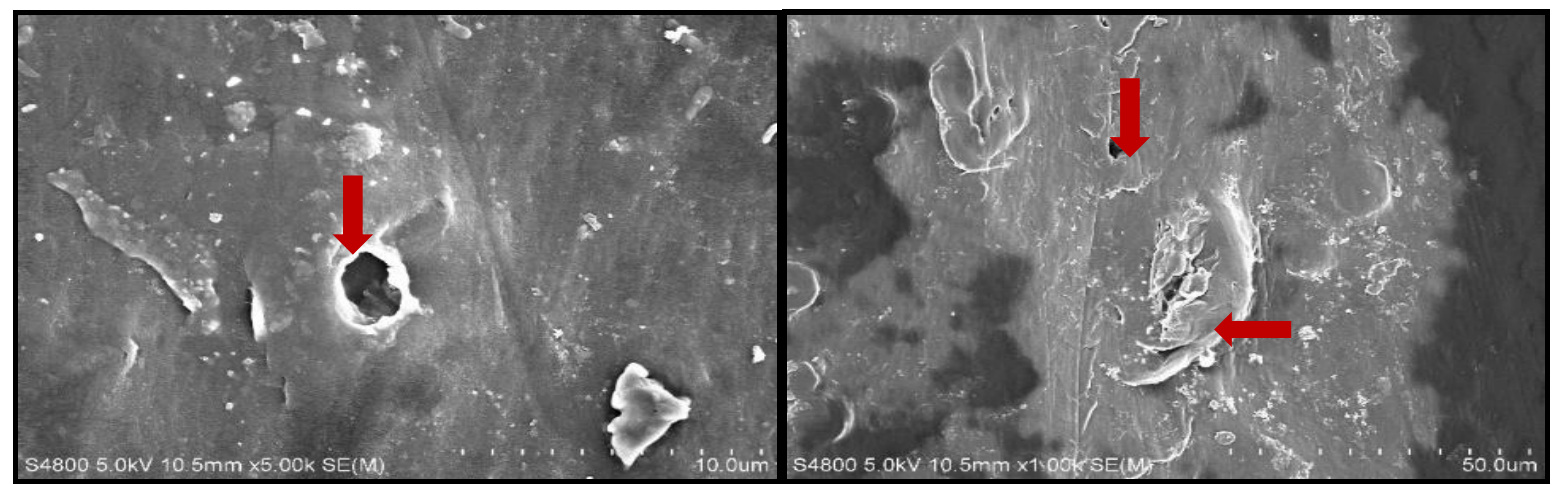

Figure.5 (b) SEM images showing degradation of LDPE sheet on two different sites by Penicillium sp. after 30 days 


\section{SEM analysis of the fungal degraded LDPE sheets}

The LDPE sheet, which was degraded by Penicillium sp. showed significant degradation (Figure 5a and 5b) indicated by the presence of porosity and fragility on the surface of the LDPE sheets over the time period of 15 days and 30 days as compared to the control LDPE sheet (Figure 6). By comparing the images obtained from the SEM, it can be said that Penicillium sp. has the ability to perform degradation of LDPE sheet under suitable condition.

Thus the study focused on the effect of fungi isolated from different plastic polluted sites on low density polyethylene (LDPE) material degradation with reference to SEM analysis

The most efficient stain was identified as Penicillium $s p$. from plastic dumping sites. The isolate was selected based on its ability to form a clear zone around them in the media containing polymer (PEG) and was used further to check its ability to degrade LDPE sheets. The ability of this isolate to degrade the LDPE sheets was studied during the course of 15 and 30 days after inoculating the fungalisolate in MSMB with pre weighed LDPE sheets under the laboratory conditions.

The biodegradation of LDPE sheets was determined by the weight reduction. Finally, after the end of the incubation period the percent weight reduction of the LDPE sheets were calculated, and it was found that Penicillium $s p$. showed weight reduction up to $20 \%$ and $50 \%$ after 15 and 30 days respectively. Finally, the degradation of LDPE sheets was confirmed by performing the scanning electron microscopy which showed porosity and fragility on the surface of the sheets, thereby concluding that Penicillium $s p$. has the ability to perform degradation of LDPE sheet.
These observations can be helpful to find solution to degrade plastic in an eco-friendly manner by further optimizing the process.

\section{Acknowledgements}

The authors are grateful to Dr. Sister M. Rashmi A.C. Principal, Patna Women's College, Patna for providing the necessary infrastructural facility. Special thanks to IIT Patna (Bihta) for the SEM Analysis.

\section{References}

Andrady A. L., Neal M. A. 2009. Applications and societal benefits of plastics. Phil. Trans. R. Soc. B., 364: pp. 1977-1984.

Aneja. K. R. 2003. Experiments in Microbiology Plant Pathology and Biotechnology. $4^{\text {th }}$ edition, New Age International (P) Limited Publisher.

Barnes DK, Galgani F, Thompson RC, Barlaz M. 2009. Accumulation and fragmentation of plastic debris in global environments; Philos. Trans. R. Soc. Lond. B 9 Biol. Sci. 364 (1526): pp. 1985-98.

Contat-Rodrigo IL, RibesGreus A. 2002. Biodegradation studies on LDPE filled with biodegradable additives: morphological changes. J Appl Polym Sci. 83: pp.16831691.

Das.M. P and Kumar.S. 2014. Microbial degradation of Low-density polyethylene by Aspergillus and Fusarium sp., IntJ.ChemTech Res.6(1): pp. 299-300.

El Shafei. H., El Nasir, N.H.A., Kansoh. A.L and Ali. 1998., Biodegradation of disposable Polyethylene by fungi Streptomyces species. Polym. Degrad. Stabil. 62: pp. 361-365.

Immanuel. O.M, Ibienne A. and Stanley H. O. 2014.Enhanced biodegradation of polyethylene by fungus isolated from the koluama mangrove swamp in the Niger delta,J.Microbiol.Biotech.Res.,4 (2): pp.1-9.

Iranzo, M., Sainz-Pardo, I., Boluda, R., Sanchez, J., Mormeneo, S. 2001. The use of microorganisms in environmental remediation. Ann. Microbiol. 51: pp. 135143. 
Jensen, William B. 2008. "Ask the Historian: The origin of the polymer concept". Journal of Chemical Education. 85 (5): pp.624-625.

Joel F.R. 1995. Polymer Science and Technology: Introduction to Polymer Science, Eds. 3, Pub: Prentice Hall PTR Inc, Upper Saddle River, New Jersey 07458: pp. 4-9.

Kiehl, J.T., Kevin E. Trenberth. 1997. Earth's annual global mean energy budget; (PDF). Bulletin of the American Meteorological Society. 78 (2): pp.197-208.

Kyaw BM, Champakalakshmi R, Sakharkar MK, Lim CS, Sakharkar KR. 2012. Biodegradation of Low- Density Polythene (LDPE) by Pseudomonas Species. Indian J Microbiol. 52(3): 411-419.

MukredMd A, HamidAbd A, Hamzah A. Yusoff W M W. 2008. Pakistan Journal of Biological Sciences 11 (13); pp. 1708-1712.

Munir, E, Harefa, RSM, Priyani, N, Suryanto, D. 2018. Plastic Degrading Fungi Trichoderma viridae and Aspergillus nominus isolated from the local landfill soil in Medan, IOP Conference Series: Earth and Environmental Science 126(2018)012145: pp. 1-7.

N. Raaman, N. Ranjitha, A. Jayshree and R. Jegadeesh. 2012. Biodegradation of plastic by Aspergillus spp. isolated from polythene polluted sites around Chennai, J.Acad.Indus. Res. 1(16): pp. 313-316.

Nishida H, Tokiwa Y. 1993. Distribution of $\operatorname{poly(ß-hydroxybutyrate)}$ and $\operatorname{poly}(\varepsilon$ caprolactone) aerobic degrading environments. J. Environ Polym Degrad; 1: pp.223-33.

Ojha N, P. Neha, Singh S, Burla A, Khatua P, Rai $\mathrm{V}$ and Bose S. 2017. Evaluation of HDPE and LDPE degradation by fungus, implemented by statistical optimization. Sci. Rep. 7: 39515 .
Otake Y, Kobayashi T, Asabe H, Murakami N. 1998. Studies on biodegradation of LDPEobservation of LDPE films scattered in agricultural fields or in garden soil.10 Polym Degrad Stab., 60: pp.79-84.

Rummel CD, Jahnke A, Gorokhova E, K ühnel D, Schmitt-Jansen M. 2017. Impacts ofbiofilm formation on the fate and potential effects of microplastic in the aquatic environment. Environ Sci Technol Lett 4(17): pp. 258-267.

Sen, K. S and Raut, S. 2015. Microbial degradation of low-density polyethylene (LDPE): A review, Journal of Environmental Chemical Engineering,(3): pp.462-473.

Shah, A.A. 2007. Role of microorganisms in biodegradation of plastics. Ph.D. thesis. Department of Microbiology, Quai-i-Azam University,Islamabad, Pakistan.pp.83-101.

Vaughan Gwynne H.C.I \&Barnes.B. 2004. Fungi Their Structure and Development, Chawla Offset Printers, Biotech Books: pp.: 175.

Vert, Michel; Doi, Yoshiharu; Hellwich, KarlHeinz; Hess, Michael; Hodge, Philip; Kubisa, Przemyslaw; Rinaudo, Marguerite; Schué, François. 2012. Terminology for bio-related polymers and applications (IUPAC Recommendations 2012). Pure and Applied Chemistry. 84 (2): pp.377-410.

Vinay BR, Uzma M, Govindappa M, Vasantha R.A, Lokesh, S. 2016. Screening and identification of polyurethane (PU) and lowdensity polyethylene (LDPE) degrading soil fungi isolated from municipal solid waste. International Journal of Current Research ,8: pp. 34752-34761.

Wilkes RA, Aristilde L. 2017. Degradation and metabolism of synthetic plastics and associated products by Pseudomonas sp.: capabilities and challenges. J Appl Microbiol., 123(3): pp. 582-593.

\section{How to cite this article:}

Jaya Philip, Tanuja, Harshita Michael, Vanshika Verma and Anam Rahman. 2020. Effect of Fungi Isolated from Different Plastic Polluted Sites on Low Density Polyethylene Material Degradation with Reference to SEM Analysis. Int.J.Curr.Microbiol.App.Sci. 9(06): 3149-3157. doi: https://doi.org/10.20546/ijcmas.2020.906.377 